\title{
Use of cholestyramine in treatment of children with familial hypercholesterolaemia
}

\author{
RICHARD J. WEST and JUNE K. LLOYD \\ From the Department of Child Health, Institute of Child Health, University of London, \\ 30 Guilford Street, London
}

\begin{abstract}
West, R. J., and Lloyd, J. K. (1973). Archives of Disease in Childhood, 48, 370. Use of cholestyramine in treatment of children with familial hypercholesterolaemia. 19 children with heterozygous familial hypercholesterolaemia have been treated with cholestyramine administered twice daily in a total dosage of 8 to $24 \mathrm{~g}$ /day ( 0.3 to $1.1 \mathrm{~g} / \mathrm{kg}$ body weight per day). Serum cholesterol concentration was reduced by a mean of $36 \%$ (range 27 to $47 \%$ ). The therapeutic effect was similar whether or not dietary fat was restricted, and the reduction in serum cholesterol has been maintained for periods of up to 20 months.

Side effects of cholestyramine have been confined to the gastrointestinal tract. Absorption of fat was impaired in some patients, but has not been associated with diarrhoea. Serum folate levels have decreased in all patients, and 6 out of 12 tested have had subnormal red blood cell folate. There has been no evidence of malabsorption of other vitamins or of minerals. Growth rate has been normal in all children.
\end{abstract}

Familial hypercholesterolaemia (familial hyperlipoproteinaemia Type II) is associated with an increased risk of ischaemic heart disease in early life (Slack, 1969). It is not yet proven that reduction in serum $\beta$-lipoprotein, and hence cholesterol, will prevent or delay the development of coronary atheroma, but if such reduction is to have maximum effect it should probably be introduced as early in life as possible, that is, during childhood (Lloyd and Wolff, 1969; Kannel and Dawber, 1972).

Any treatment used should be safe, acceptable to both the child and his parents, and maintain its effect in the long term. The degree of reduction in serum cholesterol that should be achieved is not established, but if the suggestions of Drash (1972) are accepted, then serum cholesterol should probably be lowered to below $235 \mathrm{mg} / 100 \mathrm{ml}$.

Dietary treatment has been the main form of therapy used in childhood to date. Segall et al. (1970) showed that reduction in ordinary dietary fat (largely saturated) to about $15 \mathrm{~g} /$ day achieved a mean reduction in serum cholesterol of around $22 \%$. Polyunsaturated fatty acids, taken in the form of corn oil, have no specific hypocholestero-

Received 25 September 1972. laemic effect, but corn oil was useful in improving the palatability of the low-fat diet. Because the reduction in serum cholesterol obtained was judged inadequate in some children, and also because long-term severe restriction of dietary fat is unpleasant and difficult to maintain, other forms of treatment require investigation. Clofibrate (chlorophenoxyisobutyrate) was used by Segall et al. (1970) in conjunction with dietary treatment, and proved acceptable and without demonstrable side effects over an 8-month period. However, it had only a weak hypocholesterolaemic effect, achieving a further $10 \%$ reduction in serum cholesterol over that produced by diet alone.

Cholestyramine is a nonabsorbable anion exchange resin which binds bile acids in the small intestine, thus preventing their reabsorption by the ileum and increasing faecal loss. To compensate for this loss, hepatic synthesis of bile acids from cholesterol increases and serum cholesterol falls. Cholestyramine has been used for the treatment of adults with hypercholesterolaemia (Blacket, Woodhill, and Brown, 1964; Hashim and Van Itallie, 1965; Howard, Brusco, and Furman, 1966; Fallon and Woods, 1968; Jepson, et al., 1969; Fredrickson and Levy, 1970) and is probably the most effective agent currently available. There is 


\section{Use of cholestyramine in treatment of children with familial hypercholesterolaemia}

little information, however, on the use of cholestyramine in children with hypercholesterolaemia. Horan, DiLuzio, and Etteldorf (1964) reported its short-term use in two sibs of 11 and 13 years, and Kwiterovich, Levy, and Fredrickson (1970) briefly mentioned its use in a few children. Cholestyramine is a bulky resin, and earlier preparations had a fishy taste and smell so that palatability was a serious problem. More recently, an orangeflavoured preparation, Questran, ${ }^{\star}$ has become available which, though still relatively unpalatable because of bulk and consistency, is acceptable to the majority of children. This paper reports our experience in the treatment of 19 children with the heterozygous form of familial hypercholesterolaemia using cholestyramine.

\section{Patients and methods}

Nineteen children from 11 families (12 boys, 7 girls) aged 1 to 14 years with heterozygous familial hypercholesterolaemia have been treated with cholestyramine for periods up to 20 months.

Most of the children were referred because of a family history of the early onset of ischaemic heart disease. All were asymptomatic, but one 13-year-old boy was detected because of skin xanthomata behind the knees, and one 9-year-old girl had corneal arcus. All patients had characteristic biochemical evidence of familial hypercholesterolaemia (Type IIa in the WHO classification, 1970), that is, a raised serum cholesterol and a normal fasting triglyceride level, together with increased $\beta$-lipoprotein shown by electrophoresis and density gradient ultracentrifugation. Additionally, at least one of the parents had the same lipoprotein abnormality or had died of ischaemic heart disease.

Cholestyramine was given twice daily before meals to all patients, initially starting with a dose of $4 \mathrm{~g}$ twice daily and subsequently increasing the dose until adequate therapeutic effect was achieved, or until the maximum amount that could be tolerated was being taken. The final total dosage ranged from 8 to $24 \mathrm{~g} /$ day, and, expressed on a body weight basis, varied from 0.3 to $1 \cdot 1 / \mathrm{kg}$ per day. A twice-daily regimen, pro-

^Bristol Laboratories, Langley, Bucks. vided that therapeutic response was adequate, was considered preferable to more frequent administration for children in order to avoid the necessity of taking medicine at school.

In 4 patients a comparison of the effects of twice-daily therapy with administration four times daily (the generally recommended regimen) was made. Cholestyramine was started with a dose of $4 \mathrm{~g}$ four times daily before food; serum cholesterol was measured on two occasions in each patient between 8 and 11 days after starting therapy; the administration of cholestyramine was then changed to $8 \mathrm{~g}$ twice daily (total dose unaltered) and serum cholesterol was determined on two further occasions between 5 and 10 days after the change.

In 11 patients cholestyramine therapy was combined with a diet low in saturated fat (less than $20 \mathrm{~g}$ daily) and containing some supplementary corn oil and corn oil products. 8 patients remained on a normal diet during cholestyramine therapy.

Serum cholesterol was determined by a ferric chloride autoanalyser method (Fosbrooke and Pringle, 1970), and serum triglyceride by a quantitative gas liquid chromatographic procedure (Fosbrooke and Tamir, 1968). Serum electrophoresis was done on either paper or agarose, and ultracentrifugal separation by the density gradient method of Cornwell et al. (1961). Faecal fat was estimated on pooled 3-day collections by a modification of the method of van de Kamer, ten Bokkel Huinink, and Weyers (1949).

\section{Results}

Effect of cholestyramine on serum cholesterol concentration. The scrum cholesterol concentration was lowered in all patients. The mean pretreatment value of $377 \mathrm{mg} / 100 \mathrm{ml}$ (SD 46) for the group as a whole fell to $243 \mathrm{mg} / 100 \mathrm{ml}$ (SD 21); this represented a mean reduction of $36 \%$ (range 27 to $47 \%$ ).

Influence of dietary fat restriction on effect of cholestyramine. Table I shows that there was no significant difference between the reduction in serum cholesterol achieved in the group of children treated with dietary fat restriction in addition to cholestyramine, and the reduction in

TABLE I

Comparison of reduction in serum cholesterol by cholestyramine in 2 groups of patients on different diets

\begin{tabular}{|c|c|c|c|c|c|c|}
\hline Diet & $\begin{array}{l}\text { No. of } \\
\text { patients }\end{array}$ & $\begin{array}{c}\text { Age (yr) } \\
\text { (mean and range) }\end{array}$ & $\begin{array}{c}\text { Serum cholesterol } \\
\text { pretreatment } \\
(\text { mean } \pm S D) \\
(\mathrm{mg} / 100 \mathrm{ml})\end{array}$ & $\begin{array}{c}\text { Serum cholesterol } \\
\text { on treatment } \\
\text { (mean } \pm S D) \\
(\mathrm{mg} / 100 \mathrm{ml})\end{array}$ & $\stackrel{\%}{\%}$ & $\begin{array}{c}\text { Daily dose of } \\
\text { cholestyramine } \\
(\text { mean } \pm S D) \\
(\mathrm{mg} / \mathrm{kg} \text { body } \mathrm{wt})\end{array}$ \\
\hline $\begin{array}{l}\text { Low saturated fat } \\
<20 \mathrm{~g} / \text { day } \\
\text { Normal }\end{array}$ & $\begin{array}{r}11 \\
8\end{array}$ & $\begin{array}{c}5 \cdot 9 \\
(1 \cdot 3-13 \cdot 1) \\
7 \cdot 8 \\
(5 \cdot 6-9 \cdot 9)\end{array}$ & $\begin{array}{l}375 \pm 40 \\
379 \pm 50\end{array}$ & $\begin{array}{l}245 \pm 20 \\
240 \pm 23\end{array}$ & $\begin{array}{l}35^{\star} \\
37 \star\end{array}$ & $\begin{array}{l}0.61 \pm 0 \cdot 26^{\star} \\
0 \cdot 70 \pm 0 \cdot 17^{\star}\end{array}$ \\
\hline
\end{tabular}

^Not significantly different. 
those treated with cholestyramine alone. Neither was there a significant difference between the dosage of cholestyramine given to the two groups.

In 5 patients in whom reduction in serum cholesterol had been achieved by diet together with cholestyramine, the amount of dietary fat was subsequently increased. In none of these patients was the increase in fat intake followed by a rise in serum cholesterol concentration. Fig. 1 illustrates the response in one such patient, a boy aged 4.4 years at the start of treatment. From a pretreatment level of $379 \mathrm{mg} / 100 \mathrm{ml}$ the serum cholesterol concentration fell to $213 \mathrm{mg} / 100 \mathrm{ml}$ (mean of 3 observations over a 6-month period) on a strict low fat diet ( $14 \mathrm{~g} /$ day) together with cholestyramine $8 \mathrm{~g}$ twice daily; when the dietary fat was increased to a near normal intake ( 35 to $40 \mathrm{~g}$ /day), leaving the cholestyramine dosage unaltered, the serum cholesterol concentration remained virtually unchanged at $209 \mathrm{mg} / 100 \mathrm{ml}$ (mean of 4 observations over a 10-month period).

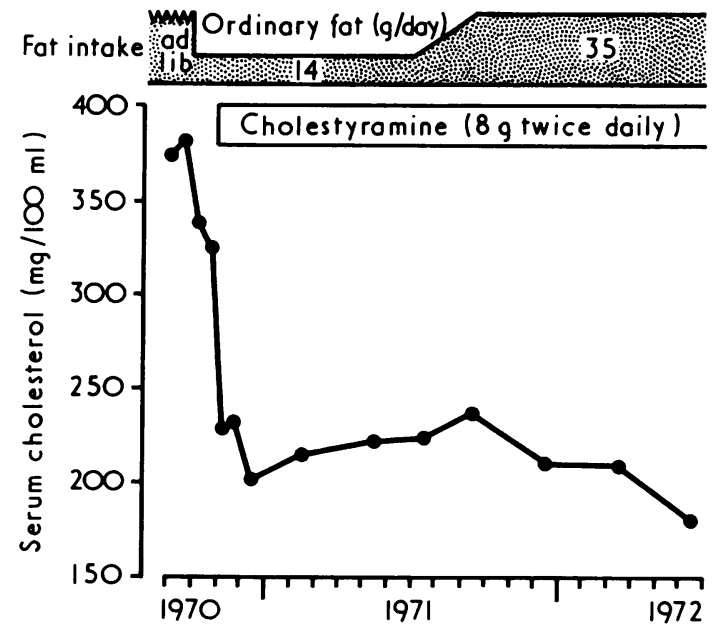

FIG. 1.-Effect on serum cholesterol of cholestyramine treatment of a 4-year-old boy with familial hypercholesterolaemia, initially combined with reduction in ordinary dietary fat to $14 \mathrm{~g} /$ day, and with subsequent increase in dietary fat to $35 \mathrm{~g} /$ day.

Comparison between twice daily and four times daily administration of cholestyramine. Table II shows that in 4 patients the hypocholesterolaemic effect of cholestyramine was the same whether it was given four or two times daily, the total dosage remaining the same.

Effect of cholestyramine on absorption. Faecal fat was estimated in 9 patients receiving
TABLE II

Comparison of hypocholesterolaemic effect of cholestyramine given twice and four times daily

\begin{tabular}{|c|c|c|c|}
\hline No. of patients & $\begin{array}{c}\text { Serum } \\
\text { cholesterol } \\
\text { pretreatment }\end{array}$ & $\begin{array}{c}\text { Serum } \\
\text { cholesterol on } \\
\text { cholestyramine } \\
4 \mathrm{~g} \text { four times } \\
\text { daily } \\
(\mathrm{mg} / 100 \mathrm{ml}) \\
(\text { mean } \pm \mathrm{SD})\end{array}$ & $\begin{array}{c}\text { Serum } \\
\text { cholesterol on } \\
\text { cholestyramine } \\
8 \mathrm{~g} \text { twice daily } \\
\\
(\mathrm{mg} / 100 \mathrm{ml}) \\
(\text { mean } \pm \mathrm{SD})\end{array}$ \\
\hline 4 & $387 \pm 20$ & $253 \pm 12$ & $250 \pm 30$ \\
\hline
\end{tabular}

cholestyramine; in 8 of these, faecal fat had also been estimated before treatment. Fig. 2 shows that 5 out of 7 children on a normal fat intake had steatorrhoea with mean faecal fat ranging from 5.3 to $10.5 \mathrm{~g} /$ day. No child on a low fat intake had abnormal levels of faecal fat. In 1 patient faecal fat of $0.9 \mathrm{~g} /$ day on a low fat $(14 \mathrm{~g})$ diet increased to $10 \mathrm{~g}$ /day when he was eating a normal diet; his cholestyramine dose was unchanged.

Steatorrhoea has so far been asymptomatic even in the 2 patients with faecal fat over $10 \mathrm{~g} /$ day, both of whom have now been followed up for over 12 months. In all patients, growth in height and weight has continued along the pretreatment centiles, with no change in velocity. Serum folate levels have decreased in all patients and 6 out of 12 tested have had subnormal red cell folate levels.

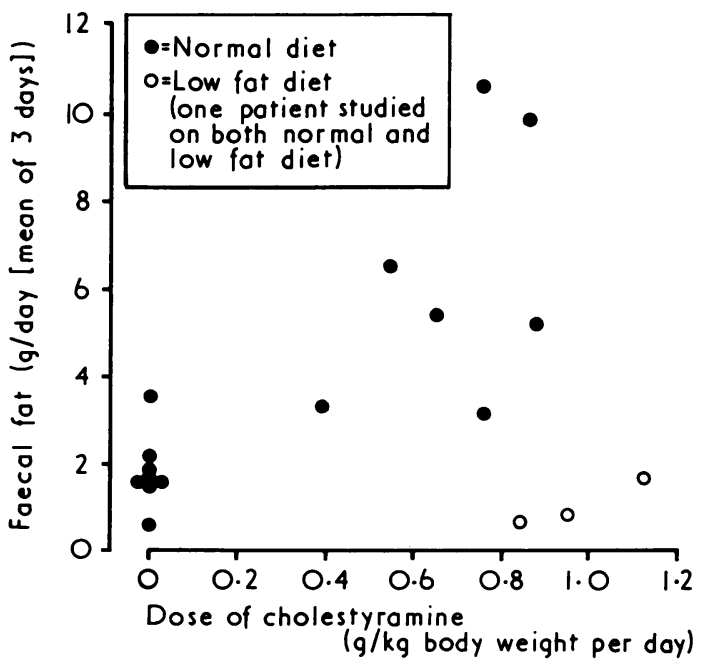

FIG. 2.-Relation between cholestyramine administration and faecal fat excretion in children with heterozygous hypercholesterolaemia. 
None, however, has so far developed anaemia, and haemoglobin, prothrombin time, serum calcium, alkaline phosphatase, and serum vitamin A concentrations have remained unchanged.

\section{Discussion}

The reduction of serum cholesterol (mean 36\% range 27 to $47 \%$ ) achieved in the present study is similar to that previously obtained in our department by the combined use of a low saturated fat diet, corn oil, and clofibrate (mean $33 \%$, range 25 to $41 \%$ ) (Segall et al., 1970). Furthermore, 8 of the patients have now been treated for over 1 year, and there has been no tendency for the control of serum cholesterol to 'escape'.

Treatment of adults with familial hypercholesterolaemia using 12 to $36 \mathrm{~g}$ cholestyramine daily in 3 or 4 doses has resulted in reductions in serum cholesterol varying between 15 to $30 \%$ in different series (Howard et al., 1966; Jepson et al., 1969; Fredrickson and Levy, 1970). Marked individual variations in the response to therapy have been reported and the larger reductions have not always been associated with larger doses of the drug. The doses used in the children in the present study when expressed on a body weight basis are, however, considerably greater than those used in most adult studies. The largest adult dose has probably been of the order of $0.5 \mathrm{~g} / \mathrm{kg}$ per day, whereas the mean dose for children was $0.65 \mathrm{~g} / \mathrm{kg}$ per day, ranging up to $1 \cdot 1 \mathrm{~g} / \mathrm{kg}$ per day.

Previous investigators using cholestyramine in adults have either restricted saturated fat intake (Fredrickson and Levy, 1970; Fallon and Woods, 1968), or have kept their patients on a normal diet (Blacket et al., 1964; Jepson et al., 1969). Our studies show that the degree of reduction of serum cholesterol does not depend on the dietary fat intake, and the fact that such a marked reduction can be achieved and sustained without the need for dietary modification represents a significant advance in the management of children with familial hypercholesterolaemia.

The administration of cholestyramine twice daily, rather than the recommended regimen of three to four times daily, offers considerable social advantages to children in that it is unnecessary for medicine to be taken at school; also, administration can be under parental supervision if necessary. All the parents and most of the children were in agreement in preferring twice-daily to more frequent administration. In 4 patients we were able to show that twice-daily administration was as effective as four times daily, when the total daily dose remained unchanged. The design of this experiment, which was governed by practical considerations, can be criticized on the grounds that all 4 patients started on the more frequent dose regimen rather than randomizing the order. Furthermore, only 5 to 11 days were allowed for equilibrium of serum cholesterol to be achieved. Nevertheless, it is clear from Table II that any difference in effectiveness of cholestyramine which depends on frequency of administration is so slight as to be outweighed by the advantages of less frequent administration.

Because cholestyramine is a nonabsorbable resin, its side effects are limited to the gastrointestinal tract. Some sensation of epigastric fullness immediately after taking the dose is common but transient, and has not been a problem in our patients. Constipation, a mild problem in some of the adult series has not occurred with the children; in fact there has usually been some increased stool frequency. Steatorrhoea has been shown in adults receiving cholestyramine in doses of $30 \mathrm{~g}$ /day or more (Hashim, Bergen, and Van Itallie, 1961). 5 out of 7 children in our study receiving a comparable or greater dose (in terms of body weight) and eating normal amounts of fat had some increase in faecal fat, though this was only marked in 2 . Though steatorrhoea has so far been without clinical effect, a modest restriction of fat intake may be necessary if it is felt desirable to prevent steatorrhoea.

Some malabsorption of folic acid is to be expected with cholestyramine administration because the folate anion will be bound to the resin. This is shown in our patients by the lowering of serum and red cell folate; the abnormality can be corrected by additional oral folic acid, which should probably be given to all patients receiving long-term cholestyramine therapy. No evidence of malabsorption of other vitamins or of minerals has been observed in our patients.

Interference with the absorption of some drugs by cholestyramine has been shown in animals (Gallo, Bailey, and Sheffner, 1965) and cholestyramine has, in fact, been suggested as a treatment for drug overdosage (Edwards, 1965). Drug absorption has not been investigated in our patients as none of them have required any other medication during the observation period. Provided other drugs are spaced in time from cholestyramine administration it is unlikely that serious interference will occur. The possibility of unexpected long-term side effects with cholestyramine is remote in view of its nonabsorbability, and this is an important consideration in the treatment of familial hypercholesterolaemia in children in whom treatment is likely to last throughout life. 
We are grateful to the Medical Research Council for financial support.

\section{REFERENCES}

Blacket, R. B., Woodhill, J., and Brown, W. D. (1964). The effect of cholestyramine ('MK 135') on the serum cholesterol level in man. Medical fournal of Australia, 2, 15.

Cornwell, D. G., Kruger, F. A., Hamwi, G. J., and Brown, J. B. (1961). Studies on the characterization of human serum lipoproteins separated by ultracentrifugation in a density gradient. American fournal of Clinical Nutrition, 9, 24.

Drash, A. (1972). Atherosclerosis cholesterol and the paediatrician. fournal of Pediatrics, 80, 693.

Edwards, K. D. G. (1965). The use of oral ion exchange resins in drug poisoning; general hypothesis and some studies on cholestyramine versus barbiturates. Medical fournal of Australia, 2, 925.

Fallon, H. J., and Woods, J. W. (1968). Response of hyperlipoproteinemia to cholestyramine resin. Fournal of the American Medical Association, 204, 1161.

Fosbrooke, A. S., and Pringle, G. A. (1970). Improved precision for the autoanalyser determination of serum cholesterol. Clinica Chimica Acta, 30, 47.

Fosbrooke, A. S., and Tamir, I. (1968). A modified method for the preparation of methyl esters of a mixture of medium-chain and long-chain fatty acids. Clinica Chimica Acta, 20, 517.

Fredrickson, D. S., and Levy, R. I. (1970). Treatment of essential hyperlipidaemia. Lancet, 1, 191

Gallo, D. G., Bailey, K. R., and Sheffner, A. L. (1965). The interaction between cholestyramine and drugs. Proceedings of the Society for Experimental Biology and Medicine, 120, 60.

Hashim, S. A., Bergen, S. S., and Van Itallie, T. B. (1961). Experimental steatorrhea induced in man by bile acid sequestrant. Proceedings of the Society for Experimental Biology and Medicine, 106, 173.
Hashim, S. A., and Van Itallie, T. B. (1965). Cholestyramine resin therapy for hypercholesteremia. Fournal of the American Medical Association, 192, 289.

Horan, J. M., DiLuzio, N. R., and Etteldorf, J. N. (1964). Use of an anion exchange resin in treatment of two siblings with familial hypercholesterolemia. fournal of Pediatrics, 64, 201.

Howard, R. P., Brusco, O. J., and Furman, R. H. (1966). Effect of cholestyramine administration on serum lipids and on nitrogen balance in familial hypercholesterolemia. Fournal of Laboratory and Clinical Medicine, 68, 12.

Jepson, E. M., Fahmy, M. F. I., Torrens, P. E., Billimoria, J. D., and Maclagan, N. F. (1969). Treatment of essential hyperlipidaemia. Lancet, 2, 1315.

Kannel, W. B., and Dawber, T. R. (1972). Atherosclerosis as a pediatric problem. Fournal of Pediatrics, 80, 544

Kwiterovich, P. O., Levy, R. I., and Fredrickson, D. S. (1970). Early detection and treatment of familial type II hyperlipoproteinemia. Circulation, 41-42, Suppl. III, 11.

Lloyd, J. K., and Wolff, O. H. (1969). A paediatric approach to the prevention of atherosclerosis. Fournal of Atherosclerosis Research, 10, 135.

Segall, M. M., Fosbrooke, A. S., Lloyd, J. K., and Wolff, O. H. (1970). Treatment of familial hypercholesterolaema in children Lancet, 1, 641.

Slack, J. (1969). Risks of ischaemic heart-disease in familial hyperlipoproteinaemic states. Lancet, 2, 1380.

van de Kamer, J. H., ten Bokkel Huinink, H., and Weyers, H. A. (1949). Rapid method for determination of fat in feces. fournal of Biological Chemistry, 177, 347.

World Health Organization (1970). Classification of hyperlipidaemias and hyperlipoproteinaemias. Bulletin of the World Health Organization, 43, 891.

Correspondence to Dr. R. J. West, Institute of Child Health, 30 Guilford Street, London WC1N 1EH. 